\title{
AVALIAÇÃO ERGONÔMICA DE UMA COLHEDORA DE CANA-DE-AÇÚCAR ${ }^{1}$
}

\author{
Ergonomic evaluation of a sugarcane harvesting machine ${ }^{1}$
}

\author{
Carla Bento da Silva ${ }^{2}$, Carlos Eduardo Silva Volpato ${ }^{3}$, Luis Antônio de Bastos Andrade ${ }^{2}$, Jackson Antonio Barbosa ${ }^{4}$
}

\section{RESUMO}

Objetivou-se, no presente trabalho, realizar uma avaliação ergonômica de uma colhedora de cana-de-açúcar, localizada no município de Barra Bonita, estado de São Paulo, em janeiro de 2007. A avaliação ergonômica foi conduzida em uma colhedora de canade-açúcar que apresentou produtividade de 831,84 ton dia $^{-1}$ na safra de 2006/2007, com base no manual Ergonomic Guidelines for Forest Machines (Skogforsk, 1999), segundo o qual os itens avaliados são distribuídos em cinco classes: A, B, C, D ou 0 (zero ). A melhor classificação ergonômica da colhedora foi atribuída aos itens visibilidade ampla, assento do operador e controle de clima na cabine. Os itens cabine, iluminação, controles e operação da máquina, ruído e manual do operador foram classificados como C. O item exaustão de gases e poeiras foi incluído na classe D. O pior item avaliado foi a visibilidade da soqueira, sendo classificado com zero. Assim, a avaliação ergonômica global resultou numa classificação como C, indicando a possibilidade de um trabalho produtivo, desde que pequenas alterações em seu planejamento sejam ajustadas.

Termos para indexação: Ergonomia, colheita mecânica, Saccharum spp.

\section{ABSTRACT}

The objective of this work was to evaluate a sugarcane harvesting machine, operating in a sugarcane plant located at Barra Bonita, State of São Paulo, in January 2007, which presented the best performance during the 2006/2007 crop season. The ergonomic evaluation was accomplished dased at the recommendations of the "Ergonomic Guidelines for Forest Machines" (Skogforsk, 1999), which grades each item into five classes: A, B, C, D or 0 (zero). The best ergonomic rate was achieved by the following items: wide visibility, operator seat and temperature control in work post. The items work post, illumination, commands and instruments, noise level and operator's manual were ranked as C. Gas exhaustion was classified as D. The visibility of the stem base was the worst ranked item, classified as 0 (zero). Therefore, the machine obtained an overall ergonomic classification as $\mathrm{C}$, which indicates the possibility of a productive work if a few structure items are adjusted.

Index terms: Ergonomics, harvester, sugarcane.

(Recebido em 10 de janeiro de 2008 e aprovado em 10 de agosto de 2010)

\section{INTRODUÇÃO}

A importância da mecanização nas operações agrícolas tem aumentado significativamente desde a década de 80 , intensificando-se na década de 90 . É necessário reduzir custos, aumentar o desempenho do sistema de colheita e a redução de perdas na operação. A utilização de máquinas superando o uso de mão-de-obra intensiva nas atividades de colheita agrícola é de futuro próximo.

Considerando-se a tendência de ocupação de grandes áreas e perspectivas de grande expansão do cultivo de importantes produtos agrícolas, como a cana-de-açúcar, a colheita mecanizada é de extrema importância, devido à crescente dificuldade e encarecimento de mão de obra para corte manual, pelo interesse na obtenção de aumentos nos desempenhos das operações de colheita, com consequente diminuição de custos e para serem cumpridas as leis ambientais que estão em vigor, com a diminuição proporcional da queimada até a sua extinção. O Brasil é o maior produtor mundial de cana-de-açúcar, com uma produção de 437 milhões de t na safra 2006/07 e uma previsão de 589 milhões de $t$ de cana-de-açúcar, para a safra 2009/10. A cultura da cana-de-açúcar apresentou uma área colhida de 5,8 milhões de hectares em 2006, uma produção de açúcar de 30 milhões de te 17,9 bilhões L de álcool (Agrianual, 2007).

Segundo o Brasil (2007), o Brasil possui 363 unidades produtoras entre destilarias e usinas cadastradas. A atividade sucroalcooleira absorve 3\% do total de pessoas empregadas nas atividades agrícolas em todo o Brasil, somando 800 mil cortadores de cana na safra, 200 mil operários, nas agroindústrias e mais 700 mil empregos indiretos.

O álcool é reconhecido mundialmente pelas suas vantagens ambientais, sociais e econômicas, e alguns

\footnotetext{
${ }_{1}^{1}$ Parte da Tese de Doutorado da primeira autora no Departamento de Agricultura da Universidade Federal de Lavras/UFLA '2Universidade Federal de Lavras/UFLA - Departamento de Agricultura/DAG - Lavras, MG

3Universidade Federal de Lavras/UFLA - Departamento de Engenharia/DEG - Cx. P. 3037 - 37200-000 - Lavras, MG - volpato@deg.ufla.br ${ }^{4}$ Universidade Federal de Lavras/UFLA - Departamento de Engenharia/DEG - Lavras, MG
} 
países do primeiro mundo já estão interessados na tecnologia brasileira (Campanhão et al., 2005).

Segundo Cana... (2005), existe um movimento dentro do setor sucro-alcooleiro para tornar a colheita da canade-açúcar totalmente mecanizada uma realidade nos próximos anos. Na região Sudeste, onde se concentra mais de $70 \%$ da produção de cana-de-açúcar do país, cerca de $40 \%$ da colheita é feita por meio da mecanização. Em outros estados, como Goiás, Mato Grosso e Mato Grosso do Sul, esses índices são maiores devido às lavouras serem mais recentes. Todavia, o setor carece de mão de obra qualificada, que possibilite atender à uma crescente demanda.

O processo de mecanização exige que o operário esteja plenamente adaptado ao posto de trabalho para poder exercer sua a função e vice-versa, sendo a ergonomia a ciência que estuda o melhor meio de adaptar o trabalho, seus instrumentos, equipamentos, máquinas e dispositivos para o trabalhador pela análise do ciclo de trabalho do operador. Esse estudo visa melhorar o ambiente de trabalho, para que seja mais seguro e confortável.

A ergonomia tem contribuído significativamente para a melhoria das condições de trabalho humano. Entretanto, na maioria dos países em desenvolvimento, a ergonomia é um conceito relativamente novo e essa contribuição ainda é pequena, em função do baixo número de estudos e da restrita divulgação dos seus benefícios (Minetti et al., 1998).

Máquinas adequadas são os melhores recursos do trabalhador agrícola, sendo essenciais para um trabalho confortável, mantendo a saúde e o bem-estar, levando a um aumento de rendimento, diminuição dos riscos de acidentes e melhor qualidade do trabalho. As máquinas e ferramentas são, muitas vezes, produzidas sem levar em consideração detalhes anatômicos do operador, posição normal de uso, distribuição ideal de peso e características específicas. Muitas máquinas importadas são adaptadas às condições ergonômicas de operadores de sua região de origem, sem ao menos serem cogitadas diferenças antropométricas, de relevo, clima e vegetação, presentes nas condições brasileiras de trabalho (Fiedler et al., 1997).

Objetivou-se, neste trabalho, realizar uma avaliação ergonômica de uma colhedora de cana-deaçúcar, enfocando-se principalmente condições mais seguras, saudáveis e confortáveis de seus operadores, facilitando a tomada de decisão na escolha de sistemas, máquinas e equipamentos de colheita de cana-deaçúcar.

\section{MATERIAL E MÉTODOS}

\section{Área de estudo}

Os dados foram coletados em uma usina localizada no município de Barra Bonita, estado de São Paulo, em Janeiro de 2007. Localizado a uma latitude $22^{\circ} 29^{\prime} 41^{\prime \prime}$ sul e a uma longitude 48 $33^{\prime} 29^{\prime \prime}$ oeste. A altitude do local é de 457 metros e seu relevo é ondulado. O clima, segundo a classificação de Köppen, é o Cfb. A temperatura média anual mínima é de $11^{\circ} \mathrm{C}$, a média de $22^{\circ} \mathrm{C}$ e a máxima de $31^{\circ} \mathrm{C}$. A precipitação média anual é em torno de $1298 \mathrm{~mm}$; o déficit hídrico é inferior a $150 \mathrm{~mm}$ anuais. Os solos predominantes da região são as argilas arenosas avermelhadas. As formações vegetais predominantes são as espécies rasteiras.

\section{Sistema de colheita de cana-de-açúcar}

O sistema de colheita é mecanizado, sendo planejado por meio de um software que indica qual a melhor época para se realizar essa operação para cada bloco de plantio (variedade, idade, aplicação de vinhaça, reforma, tipo de colheita, etc). A partir dessas informações, é feito um ajuste manual visando o melhor roteiro a ser seguido dentro da área operacional, para se evitar excesso de mudanças das frentes de corte.

\section{Colhedora avaliada}

A usina dispõe de três colhedoras de cana-deaçúcar de diferentes marcas e características, sendo escolhida para a avaliação ergonômica a que apresentou uma capacidade operacional de 831,84 ton dia $^{-1}$ na safra de 2006/2007.

A colhedora avaliada apresenta as características operacionais listadas na Tabela 1.

Tabela 1 - Dados operacionais sobre a colhedora de canade-açúcar avaliada.

\begin{tabular}{ll}
\hline \multicolumn{1}{c}{ Parâmetro } & Característica operacional \\
\hline Rodado & Pneumático \\
Motor & 6 cilindros \\
Potência do motor & $336 \mathrm{CV}, 2000 \mathrm{rpm}$ \\
Admissão de ar & Turbo-alimentação \\
Pós-resfriamento & $\mathrm{Ar}-$ ar \\
Combustível & Óleo diesel fossil \\
Tanque de combustível & 570 litros \\
Bateria & 2 unidades, 24 V cada \\
\hline
\end{tabular}




\section{Avaliação ergonômica de máquinas colhedoras de cana- de-açúcar}

Uma vez que não existe um manual específico de avaliação ergonométrica para colhedoras de cana-deaçúcar, a máquina em questão foi avaliada segundo as diretrizes ergonômicas contidas no manual de classificação ergonômica Ergonomic Guidelines for Forest Machines (Skogforsk, 1999), sendo as medidas realizadas com o auxílio de uma trena graduada em centímetros. Os seguintes itens foram avaliados;

Acesso ao posto de trabalho - observação e medida dos meios de acesso;

Cabine - medição das dimensões da cabine (altura e largura); Visibilidade - medição das dimensões dos vidros e espelhos disponíveis e da capacidade de visibilidade do material a ser cortado (soqueira);

Iluminação - número de faróis, seu direcionamento e capacidade de iluminação;

Assento do operador - medição das alturas do assento do operador e observação de presença ou não de apoio de braços, encosto de cabeça, entre outros;

Comandos e instrumentos - observação visual de todos os comandos e instrumentos e suas respectivas funções (com auxílio do manual do operador);

Ruído - medição dos decíbeis com decibelímetro, marca SPER Scientific, modelo SPER 840029. A medida foi realizada à distância de um palmo do ouvido $(0,2 \mathrm{~m})$ do operador, sendo feitas 10 repetições, medidas em intervalos de 30 segundos da mesma operação. A obtenção de valores médios de nível de ruído foi feita por meio do cálculo do nível equivalente $\left(\mathrm{L}_{\mathrm{eq}}\right)$, conforme NR-15. Esse valor corresponde ao valor integrado dos níveis de ruído isolados obtidos em intervalos de tempo constantes. Na obtenção de valores de nível de pressão sonora com o decibelímetro, durante certo intervalo de tempo, ocorrem variações nesses valores, visto que esse aparelho apresenta o resultado instantâneo de pressão sonora. $\mathrm{O} \mathrm{L}_{\mathrm{eq}}$ retorna um valor único que, caso se mantivesse constante durante o mesmo intervalo de tempo, resultaria na mesma quantidade de energia sonora presente durante a coleta dos dados variados anteriormente. É obtido por meio da Equação 1:

$$
\mathrm{L}_{\mathrm{eq}}=10 \cdot \log \left(\frac{1}{\mathrm{n}} \cdot \sum_{\mathrm{i}=1}^{\mathrm{n}} \mathrm{f}_{\mathrm{i}} \cdot 10^{0,1 \cdot \mathrm{L}_{\mathrm{i}}}\right)
$$

Em que:

$\mathrm{L}_{\mathrm{eq}}=$ nível de ruído equivalente, em $\mathrm{dB}(\mathrm{A})$;

$\mathrm{n}$ = número de medições válidas;

fi $=$ frequência do ruído $\mathrm{Li}$, e
Li = nível de ruído medido a cada 10 segundos, em $\mathrm{dB}(\mathrm{A})$.

Controle de clima na cabine - observação da presença ou ausência do climatizador de ar na cabine, suas velocidades e termostato;

Exaustão de gases e poeiras - observação do design do escapamento e o sentido de direcionamento da fumaça; Manual do operador - observação no manual do operador das instruções escritas e fichas de recomendação.

Em função do exame desses itens, as colhedoras foram enquadradas nas classes da Tabela 2, de acordo com o manual de Skogforsk (1999):

As diretrizes são escritas com referência à classe $\mathrm{A}$ e, portanto, descrevem os requerimentos mais restritos. Em algumas seções, que requerem o uso de equipamento de medição que não está prontamente disponível, as diretrizes foram divididas em duas seções, uma opcional, baseada em medições, e a outra obrigatória, baseada na avaliação subjetiva, que tem que ser feita em qualquer caso.

Os itens sujeitos à avaliação qualitativa foram classificados em relação à sua adequação aos padrões ergonômicos recomendados. O dado relativo a ruído (avaliação quantitativa) foi confrontado com as diretrizes ergonômicas e com os limites máximos de exposição determinados pela NR - 15 (CLT).

\section{RESULTADOS E DISCUSSÃO}

\section{Avaliação ergonômica da colhedora de cana-de-açúcar}

\section{Acesso ao posto de trabalho}

Os degraus são em número de seis, sendo cinco em escada reta (com distâncias de $26 \mathrm{~cm}$ do primeiro ao segundo, $23 \mathrm{~cm}$ do segundo ao terceiro e $25 \mathrm{~cm}$ do terceiro ao quarto e do quarto ao quinto) e um à direita da entrada da cabine, de dimensões $28 \mathrm{~cm}$ de altura e $63 \mathrm{~cm}$ de comprimento. A distância do primeiro degrau ao solo é de $58 \mathrm{~cm}$, totalizando uma altura de $1,83 \mathrm{~m}$ da plataforma ao chão.

$\mathrm{O}$ acesso à cabine é feito pelos dois lados, pelas escadas laterais. A abertura da porta é lateral e de difícil manejo, obrigando o operador a se deslocar para outro degrau acima do nível da cabine para então afastar a porta e depois entrar. A largura maior da porta é de $58 \mathrm{~cm}$, com altura de $1,50 \mathrm{~m}$.

Segundo Skogforsk (1999), esse item não está dentro das normas consideradas seguras ergonomicamente, pois o acesso não é muito fácil e nem seguro. Como o meio de acesso é inconveniente, os operadores são tentados a pular para baixo, o que, com o tempo, pode resultar em danos aos quadris, joelhos ou pés. Acesso mal projetado também 
pode se constituir em obstáculo para operadores mais velhos. Isso pode desestimulá-los a não deixar a cabine para fazer uma pausa ou algum trabalho requerido fora da cabine como, por exemplo, mudar um elo da serra.

Ainda segundo o mesmo autor, o operador também deve ser capaz de subir e descer da máquina de frente com segurança, em qualquer posição em que a cabine esteja. Os degraus têm que ter um tamanho que acomode a maior parte do pé e, pelo menos, um corrimão que proporcione apoio, por todo o lanço, deve existir. Por isso, segundo as normas ergonômicas, esse item recebeu a classificação D.

\section{Cabine}

A cabine tem altura de $1,63 \mathrm{~m}$, de piso de ferro, coberto com material emborrachado e papelão, sendo fechada com vidros.

Segundo Skogforsk (1999), uma cabine restrita ou mal projetada força o operador a trabalhar em uma postura fixa que é cansativa e, com o tempo, danosa para a saúde. O operador deve ser capaz de assumir uma posição confortável que proporcione uma boa visibilidade, na qual os controles estejam a uma distância conveniente. Deve haver amplo espaço para o descanso dos braços, controles e joelhos e pés do operador, de forma que eles não façam contato com o interior da cabine ou outros equipamentos. No caso, foi observado um espaço insuficiente, onde o operador não pode adotar posições de trabalho relativamente confortáveis. A cabine foi classificada como classe $\mathrm{C}$.

\section{Visibilidade da ampla e da soqueira pelo operador}

O para-brisa é inteiro, com dimensões de 1,60 m de largura e 1,35 de altura. Os retrovisores são em número de quatro (dois de cada lado), com dimensões de $17 \mathrm{~cm} \mathrm{x}$ $23 \mathrm{~cm}$ e $18 \mathrm{~cm}$ x $35 \mathrm{~cm}$. Seguindo as normas de classificação de Skogforsk (1999), o operador tem uma visão livre da zona de operação, sem ter que ajustar sua postura; o vidro da janela é de fácil limpeza. A visibilidade, desta forma, deveria ser classificada como B.

Entretanto, diferentemente do que acontece com a colheita florestal, onde o operador tem uma visão mais nítida do local a ser cortado, na cana-de-açúcar isso não acontece, pois o operador não consegue enxergar a soqueira. Ele simplesmente ajusta a altura de corte e enquadra a colhedora na linha de plantio. Sendo assim, a visibilidade para essa condição foi classificada como zero.

\section{Iluminação}

A máquina tem quatro faróis superiores frontais retangulares, de tamanhos iguais, e dois faróis inferiores frontais redondos. Apresenta um farol do compartimento do motor e um farol no elevador. A cabine tem luz interna. Plataforma e degraus não têm iluminação.

Segundo as diretrizes de Skogforsk (1999), a intensidade luminosa deve ser alta o suficiente e a luz deve ser direcionada de forma tal que não haja ofuscamento por contrastes ou reflexos. Por esses conceitos, esse item recebeu a classificação $\mathrm{C}$.

\section{Assento do operador}

A altura do assento do operador é de $55 \mathrm{~cm}$ (base), sem encosto de cabeça, provido de cinto de segurança. $\mathrm{O}$ material utilizado no revestimento do assento é courino. A distância do assento do operador ao para-brisa é de $73 \mathrm{~cm}$. A distância do vidro traseiro até o para-brisa é de $1,35 \mathrm{~m}$.

Tabela 2 - Classificação de máquinas agrícolas, quanto à características ergonômicas.

\begin{tabular}{cl}
\hline Classes & \multicolumn{1}{c}{ Características } \\
\hline A & $\begin{array}{l}\text { Trabalho altamente produtivo em todos os tipos de terrenos e povoamentos. Alto nível } \\
\text { tanto de segurança ativa quanto passiva. Trabalho de manutenção fácil, direto e } \\
\text { seguro. }\end{array}$ \\
\hline B & $\begin{array}{l}\text { Trabalho altamente produtivo, mas sob condições mais fáceis do que as da Classe A. } \\
\text { Alto nível de segurança ativa e passiva, mas não do mesmo padrão da classe A. }\end{array}$ \\
\hline C & $\begin{array}{l}\text { Condições mais fáceis e/ou durações mais curtas do que na Classe B. Nível alto de } \\
\text { segurança ativa e passiva, mas não do mesmo padrão da Classe B. }\end{array}$ \\
\hline D & $\begin{array}{l}\text { Condições mais fáceis e/ou durações mais curtas do que na Classe C. Nível alto de } \\
\text { segurança ativa e passiva, mas não do mesmo padrão da Classe C. }\end{array}$ \\
\hline & $\begin{array}{l}\text { A máquina não satisfaz os requerimentos de segurança e regulamentos ou tem } \\
\text { defeitos tão sérios que o operador corre um alto risco de se ferir. A máquina não deve } \\
\text { ser utilizada até que os defeitos tenham sido corrigidos e preencha os critérios } \\
\text { especificados em uma das outras classes (A-D). }\end{array}$ \\
\hline
\end{tabular}


$\mathrm{O}$ assento do operador pode ser regulado em avanço e recuo, em altura e regulagem de peso. Existem apoios escamoteáveis dos braços, com ajuste de altura. Os suportes de braço oferecem apoio, não restringindo os movimentos, podendo ser classificado como ergonomicamente bom, segundo as diretrizes ergonômicas.

O que foi observado está de acordo com o descrito por Arbetsmiljoinstituted et al. (1990), que relatam que o assento deve ter ajuste em altura, distância e comprimento. Esse item foi enquadrado na classe B.

\section{Comandos e instrumentos (controles e operação da máquina)}

Existem quatro painéis de controle e de mostradores diferentes, além dos manches e dos controles localizados ao lado direito do operador. O primeiro painel, analógico, é localizado à esquerda da vista frontal do operador, com as seguintes funções e indicadores: vacuômetro da transmissão, pressão da transmissão - lado direito, pressão da transmissão - lado esquerdo, pressão corte de base, pressão extrator primário, pressão rolos picadores e indicador da altura do corte de base.

O segundo painel localiza-se acima da cabeça do operador, e tem os seguintes comandos: inativo (opcional), acende faróis (4 superiores frontais), acende faróis ( 2 inferiores frontais), limpador de para-brisa e lavador de para-brisa.

O terceiro painel localiza-se à direita da vista frontal do operador, com as seguintes funções e indicadores: inativo (opcional), tacômetro, indicador de funções, indicador do nível de combustível, indicador da temperatura da água do motor, chave de ignição, indicador da pressão do óleo do motor, botão de partida do motor, inativo (opcional) e indicador de funções.

O quarto painel fica ao lado direito do operador, com as seguintes funções e indicadores: acelerador, afogador do motor, picador esquerdo, picador direito, liga corte de pontas, giro da biruta, sobe/desce elevador, liga extrator primário, inversão corte de pontas, acende farol do compartimento do motor, liga/desliga $2^{\mathrm{a}}$ marcha, acende farol do elevador, aciona giro-flex e acende lanternas do painel.

Nos controles do lado direito do operador localizam-se as seguintes funções: levanta/abaixa corte de pontas e plataforma, liga/inverte rolos, rolos picadores, corte de base e pirulitos, levanta/abaixa sapata direita e esquerda, flap do extrator secundário, aciona corrente do elevador.

Os dois manches localizados do lado esquerdo do volante têm os controles de deslocamento frente/ré. Ao lado direito do volante escamoteável encontram-se o freio estacionário, o freio de emergência e o manômetro do ar de freio.

Os pedais são de ferro. O pedal do giro do elevador (direito/esquerdo) localiza-se no centro, o pedal de descanso do lado esquerdo e o pedal da buzina de ar do lado direito. Os pedais apresentam extremidades ligeiramente arredondadas.

Segundo Skogforsk (1999), os controles de mão e os painéis de controle com joysticks operados manualmente devem ser projetados de tal forma que possam ser inclinados para os lados, com um formato que evite que a mão escorregue para fora, o que não acontece nessa máquina. Os controles de maior uso não apresentam apoio de braço para o operador descansar adequadamente, podendo causar uma tensão repetitiva nos ombros. Os controles pouco usados estão localizados de modo a forçar o operador a estender-se para alcançá-los, assim variando inadequadamente sua postura. Esse item recebeu a classificação C.

\section{Ruído}

Com a máquina apenas ligada, em rotação normal, foi encontrado um valor $\mathrm{L}_{\mathrm{eq}} 79,11 \mathrm{~dB}(\mathrm{~A})$, na cabine do operador. A mesma verificação foi feita com a máquina em operação, com um total de dez repetições, tendo sido encontrado um valor $\mathrm{L}_{\text {eq }}$ de $82,13 \mathrm{~dB}(\mathrm{~A})$. De acordo com a portaria CLT 3214-NR 15 (Associação Brasileira de Normas Técnicas - ABNT, 1987) para ruídos contínuos, esses valores estão dentro das normas de segurança no trabalho, que estabelece o valor de $85 \mathrm{~dB}(\mathrm{~A})$ como máxima exposição permissível para uma jornada de 8 horas. Assim sendo, esse item foi classificado como classe $\mathrm{C}$.

\section{Controle de clima na cabine}

A cabine tem ventilação, ar condicionado (termostato com tem três velocidades) e aquecedor, direcionadores giratórios de ar, difusores de ar e filtro de ar interno. Como o sistema de controle de clima é automático, com controles individualmente ajustáveis e de fácil operação. Esse item está dentro do recomendado por Skogforsk (1999), sendo enquadrado como classe B.

\section{Exaustão de gases e poeiras}

Foram constatados os seguintes aspectos:

- o escapamento está acima do nível da cabine, localizado no meio da colhedora;

- não há filtro de gases no escapamento;

- o desenho do escapamento previne a entrada de fumaça na cabine;

- catalisador e indicador de filtros são inexistentes. 
As diretrizes ergonômicas descrevem como ergonomicamente aceitável quando o desenho da cabine evita a entrada de fumaça, o sistema de exaustão está livre de vazamentos e o cano de descarga está localizado bem longe da entrada de ar da cabine. Verifica-se que, apesar do desenho do escapamento estar dentro do aceitável, os padrões encontrados são classificados como não muito satisfatórios, principalmente pela ausência de catalisador e indicador de filtros. Esse item foi classificado como D.

\section{Manual do operador}

$\mathrm{Na}$ análise das características do manual do operador, foi constatado que ele não está completamente dentro das normas ergonômicas de Skogforsk (1999), pois, entre outras coisas, o seu índice deixa a desejar, apesar de ser claramente ilustrado. Esse item recebeu a classificação C.

Apesar de apresentar alguns itens classificados como B e D; e um item zero (0) a colhedora apresentou o predomínio de itens com classificação intermediária entre essas duas classes. Assim sendo, sua avaliação final foi como classe $\mathrm{C}$.

$\mathrm{Na}$ Tabela 3, apresenta-se um resumo da classificação ergonômica da colhedora, por item avaliado.

Tabela 3 - Resumo da classificação ergonômica da colhedora.

\begin{tabular}{lc}
\hline \multicolumn{1}{c}{ Ítem } & Classe \\
\hline Acesso à cabine & $\mathrm{D}$ \\
Cabine & $\mathrm{C}$ \\
Visibilidade ampla & $\mathrm{B}$ \\
Visibilidade da soqueira pelo operador & Zero $(0)$ \\
Iluminação & $\mathrm{C}$ \\
Assento do operador & $\mathrm{B}$ \\
Controles e operação da máquina & $\mathrm{C}$ \\
Ruído & $\mathrm{C}$ \\
Controle de clima na cabine & $\mathrm{B}$ \\
Exaustão de gases e poeiras & $\mathrm{D}$ \\
Manual do operador & $\mathrm{C}$ \\
\hline
\end{tabular}

Uma das características desse manual de classificação ergonômica é que os elementos do design e função de uma máquina que influenciam as condições de trabalho do operador estão divididos em cinco classes pré-definidas. Isso pede uma medida de julgamento subjetivo, uma vez que é impossível definir claramente as classes. É necessário, para se proceder a uma avaliação consistente, algum conhecimento de ergonomia. Tanto critérios técnicos quanto subjetivos são fornecidos para cada classe. Por essa razão, métodos padronizados devem ser utilizados sempre que possível, tanto para medir quanto para interpretar os resultados.

O princípio da classificação é que o impacto de uma máquina na saúde e no bem-estar do operador deveria ser o mesmo, não importando a classe onde o item avaliado foi colocado. Isso pressupõe que a máquina esteja sendo usada para o propósito para o qual foi projetada e que foram levados em consideração a duração, o movimento e a dificuldade do trabalho. O próprio autor da classificação (Skogforsk, 1999) reconhece que muitos dos critérios da classe A não serão preenchidos ainda por alguns anos.

\section{CONCLUSÕES}

A colhedora avaliada apresentou classificação final C, portanto, não apresenta condições de trabalho ideais, sob o ponto de vista ergonômico; Sob o ponto de vista ergonômico, a colhedora tem condições de melhoria, principalmente nos itens classificados como C e D. Em relação ao item visibilidade da soqueira classificado como zero, o potencial de melhora envolve mudanças estruturais na posição da cabine.

\section{REFERÊNCIAS BIBLIOGRÁFICAS}

ARBETSMILJOINSTITUTED; FORSKINGSSTIFTELSE; SKORGSARBETEN; SLUSKOGSHOGSKOLAN. An ergonomic checklist for forestry machinery. Oskarshamn, 1990. 43p.

ASSOCIAÇÃO BRASILEIRA DE NORMAS TÉCNICAS. NBR 9999: medição do nível de ruído, no posto de operação, de tratores máquinas agrícolas. Rio de Janeiro, 1987. 11p.

BRASIL. Cana-de-açúcar e agroenergia: usinas e destilarias cadastradas. Disponível em: <http:// Www.agricultura.gov.bł>. Acesso em: 28 mar. 2007.

CAMPANHÃO, J.M.; BARBOSA, V.; DURIGAN, A.M.P.R.; MUTTON, M.A. Manejo da soqueira da canade-açúcar submetida a queima acidental da palhada remanescente da colheita mecanizada. Revista STAB, Piracicaba, v.23, n.4, p.33-37, 2005.

CANA: colheita mecanizada. Revista Rural, mar; 2007. Disponível em: <http::/Www.revistarural.com.bri. Acesso em: 28 mar. 2007. 
FIEDLER, N.C.; SOUZA, A.P.; MACHADO, C.C.;

BAÊTA, F.C.; MINETTE, L.J. Avaliação qualitativa de fatores ergonômicos em máquinas utilizadas na colheita de madeira. Revista Engenharia na Agricultura, Viçosa, v.5, n.2, p.185-193, 1997.

MINETTI, L.J.; SOUZA, A.P.; MACHADO, C.C.;

FIEDLER, N.C.; BAÊTA, F.C. Avaliação dos efeitos do ruído e da vibração no corte florestal com motosserra. Revista Árvore, Viçosa, v.22, n.4, p.325330, 1998.

SKOGFORSK. The forestry research institute of sweden: ergonomic guidelines for forest machines. Uppsala: Swedish National Institute for Working Life, 1999. 86p. 